\title{
Special feature section on spatial analysis and modeling: part II
}

\author{
Yasushi Asami ${ }^{1}$. Jean-Claude Thill ${ }^{2}$ (D) \\ Published online: 1 February 2020 \\ (c) The Japan Section of the Regional Science Association International 2020
}

This is the second of two special feature sections on spatial analysis and modeling. In September 2018, the International Conference on Spatial Analysis and Modeling was held at the University of Tokyo to promote and share studies in this field. The detailed program of this 2-day event is available at https://sam2018.wixsite.com/ home. Some of the papers presented at this conference were submitted for publication in this journal in two special feature sections. These submissions were supplemented by some other articles that fit the theme of spatial and modeling. All manuscripts were subjected to the customary review process of the journal. The first special feature section appeared in issue 2 of volume 3 of this journal.

Regional science has been defined as "a social science that is concerned with the socioeconomic workings of human societies within the context of a region" (Thill 2017). This scientific discipline differentiates itself from others by the contextualization of relationships and processes of interest with the confines of this portion of the surface of the Earth. Other social sciences may miss the ability to fully comprehend the complex relationships that may exist locally between perspectives and aspects. They may also miss the ability to understand why outcomes of processes are different at different places on the surface of the Earth. That the world and human societies are not all happening at a single location, on the head of a pin, is what constitutes the essence of Regional Science. The region is the object of study of Regional Science. It is a geographic territory, but in the words of the founding father of this field of study, Isard, it "is not merely an arbitrarily demarcated area; rather it is an area that is meaningful because of one or more problems associated with it which we as regional scientists want to examine and help solve" $(1975,1)$. Over the past 65 years, Regional Science has pursued scholarship along several lines of research that have been summarized in various publications including Thill (2017), Mulligan (2014), and others. Through this considerable volume of scholarship, several methodological perspectives, always in line with the neo-positivist tradition, have proved

Jean-Claude Thill

Jean-Claude.Thill@uncc.edu

1 The University of Tokyo, Tokyo, Japan

2 University of North Carolina at Charlotte, Charlotte, USA 
themselves to be particularly closely aligned with the purposes of Regional Science. Spatial analysis and modeling (SAM) is one of them.

It has been said that spatial analysis is "the scientific analysis of data, wherein the spatial position - whether absolute or relative, or both-of data records is explicitly accounted for" (Thill 2018). Particularly, spatial analysis emphasizes the notion of spatial differentiation and the influence of geographic position (whether absolute or relative) may have on socioeconomic phenomena. Thus, it underscores the need to analyze causal processes spatially, and the need to consider issues of spatial dependence and spatial heterogeneity associated with these phenomena. Spatial analysis does this by means of spatially explicit models that often are designed on foundations in statistics, systems engineering, artificial intelligence, machine learning, and a host of other data-centric analytical research designs and methodologies. Our understanding of urban and regional systems is uniquely enhanced by the full spectrum of methods in the toolbox of spatial analysis and modeling.

In this second special feature of the Asia-Pacific Journal of Regional Science, we collected six articles on urban and regional research from an Asia-Pacific perspective that use spatial analysis and modeling as a means to make knowledge relevant to the specific spatial and regional context they focus on.

Space and regions have been said to be constructs rather than concepts that are independent of how socioeconomic systems operate and behave spatially (Thill 2011). These constructs are therefore outputs rather than inputs to the processes under study. In their paper, Akiyama et al. (2019) study capital flows at a very fine spatial granularity in the real economy of Japan. Data for such research are typically not available to the research community, and given the spatial and temporal resolution of the data points (or flows in this case), this is an excellent case of the frontier of development of big data analytics in Regional Science. The authors develop and present an innovative method of inter-firm transaction big data analytics that opens the door to scoping the workings of the national economy at a very fine resolution. In a sense, this is the equivalent to using a microscope to probe the micro-structures of organisms. Policy implications of having access to such data through the proposed methodology are endless.

Cities are highly dynamic environments, as they concentrate a large portion of a nation's creative and innovative potential. Urban environments exhibit a footprint that reflects how the cityscape is experienced and lived by its citizens and users. The study of urban morphology conducted by Perez et al. (2019) is a good example of innovative application of spatial analysis to read the city through its morphology. The authors use multiple indicators of building characteristics in two urban regions with quite distinct social and cultural characteristics, namely Osaka-Kobe and Marseille-Provence. Techniques of exploratory spatial data analysis and of spatial clustering are innovatively leveraged to inform urban planners and managers on urban functions and urban uses.

Sustainable futures will require an energy transition from traditional energy sources (fossil or nuclear, primarily) toward more renewable energy and a mix of the two sources in between. The paper by Taniguchi (2019) treats in full detail a potential solution to the fragmentation of markets and infrastructure as a result of jurisdictional separation. To maintain the viability of local and regional economies, 
interregional trading and transfer or transmission of energy from various sources are essential. At stake is the stability of the balance between demand and supply of energy locally, and across regionally defined entities. This paper looks at the experience accumulated by Denmark and analyzes how Japan can follow the lead of this European country. The research presented focuses on the general configuration of interregional connectors and, through modeling, assesses the reduction in carbon emission that can be achieved through their systems upgrades.

Public finance is a theme of research that is central to the policy side of regional science. Extreme fragmentation of institutions and jurisdictions may increase of the cost of public service management and delivery of services to the public, although this may bring management closer to the public through decentralization and public participation. Baba and Asami (2019), use a formal economic model to study the cost savings that may result from cooperation or collaborative structures that bring together municipalities in Japan. Through this framework, they study the trade-offs that exist for different levels of cooperation, and under various types of geographic constraints. Potential savings to the citizens are particularly underscored. Chalil (2019) also studies municipal finances and compares administrative performance in Indonesia. The author uses the concept of yardstick competition, which accounts for how a particular jurisdiction fares in comparison to its neighbors, to assess voting patterns and success in this context. The core to this sort of research is the accountability that local public officials can expect when they face their constituency.

Cochrane and Poot (2019) analyze the conjecture according to which there is a positive relationship between unemployment and homeownership. They conduct an empirical analysis on New Zealand census data from 1986 to 2013. Their careful spatial econometric analysis is broadly in line with international empirical evidence presented by others for various countries that the relationship is fragile and mixed. In their thorough discussion, they contextualize the results and elaborate on the local circumstances that exhibit varied strength of the hypothesized relationship.

Through the full set of contributions on spatial analysis and modeling compiled in this issue as well as in the first installment, we have demonstrated the tremendous power of spatial thinking in social science research through the use of methods of spatial analysis and modeling. This research approach produces more analytically sound conclusions, reduces bias in explanation, and enables policymakers and decision makers to more effectively deliver on identified objectives.

\section{References}

Akiyama Y, Yamamoto Y, Shibasaki R, Kaneda H (2019) A detailed method to estimate inter-regional capital flows using inter-firm transaction and person flow big data. Asia-Pac J Reg Sci. https://doi. org/10.1007/s41685-019-00130-x

Baba H, Asami Y (2019) Estimating the minimal efficient scale and the effect of intermunicipal cooperation on service provision areas for waste treatment in Japan. Asia-Pac J Reg Sci. https://doi. org/10.1007/s41685-019-00119-6

Chalil TM (2019) Fiscal competitions among Indonesian municipalities: a spatial econometric analysis. Asia-Pac J Reg Sci. https://doi.org/10.1007/s41685-019-00138-3 
Cochrane W, Poot J (2019) Did the post-1986 decline in the homeownership rate benefit the New Zealand labour market? A spatial-econometric exploration. Asia-Pac J Reg Sci. https://doi.org/10.1007/ s41685-020-00148-6

Isard W (1975) Introduction to regional science. Prentice-Hall, Englewood Cliffs

Mulligan G (2014) Regional science at sixty: traditional topic and new directions. Australas J Reg Sci 20(1):4-67

Perez H, Fusco G, Araldi A, Fuse T (2019) Identifying building typologies and their spatial patterns in the metropolitan areas of Marseille and Osaka. Asia-Pac J Reg Sci. https://doi.org/10.1007/s4168 5-019-00127-6

Taniguchi S (2019) Examining the causality structures of electricityinterchange and variable renewable energy: a comparison between Japan and Denmark. Asia-Pac J Reg Sci. https://doi.org/10.1007/ s41685-019-00120-z

Thill J-C (2011) Is spatial really that special? A tale of spaces. In: Popovich V, Claramunt C, Devogele T, Schrenk M, Korolenko K (eds) Information fusion and geographic information systems: towards the digital ocean. Springer, Heidelberg, pp 3-12

Thill J-C (2017) Regional science. In: Castree N, Goodchild M, Liu W, Kobayashi A, Marston R, Richardson D (eds) International encyclopedia of geography. Wiley-Blackwell, Hoboken. https://doi. org/10.1002/9781118786352.wbieg0979

Thill J-C (2018) Innovations in GIS\&T, spatial analysis, and location modeling. In: Thill J-C (ed) Spatial analysis and location modeling in urban and regional systems. Springer, Cham, pp 1-6

Publisher's Note Springer Nature remains neutral with regard to jurisdictional claims in published maps and institutional affiliations. 